\title{
Rapid Generation of a Recombinant Genotype VIII Newcastle Disease Virus (NDV) Using Full-Length Synthetic cDNA
}

\author{
Kavitha Murulitharan ${ }^{1} \cdot$ Khatijah Yusoff $^{1,2} \cdot$ Abdul Rahman Omar $^{1} \cdot$ Ben P. H. Peeters ${ }^{3} \cdot$ Aidin Molouki $^{4}(\mathbb{D}$
}

Received: 11 August 2020 / Accepted: 10 February 2021 / Published online: 4 March 2021

(c) The Author(s), under exclusive licence to Springer Science+Business Media, LLC part of Springer Nature 2021

\begin{abstract}
Rescue of (-)ssRNA viruses involves the sequential assembly and cloning of the full-length cDNA, which is often a challenging and time-consuming process. The objective of this study was to develop a novel method to rapidly clone the full-length cDNA of a very virulent NDV by only one assembly step. A completely synthetic $15 \mathrm{~kb}$ cDNA of a Malaysian genotype VIII NDV known as strain AF2240-I with additional flanking BsmBI sites was synthesised. However, to completely follow the rule-of-six, the additional $\mathrm{G}$ residues that are traditionally added after the $\mathrm{T} 7$ promoter transcription initiation site were not synthesised. The synthetic fragment was then cloned into low-copy number transcription vector pOLTV5-phiX between the T7 promoter and HDV Rz sequences through digestion with BbsI. The construct was co-transfected with helper plasmids into BSRT7/5 cells. A recombinant NDV called rAF was successfully rescued using transfection supernatant harvested as early as $16 \mathrm{~h}$ post-transfection. Virus from each passage showed an intracerebral pathogenicity index (ICPI) and a mean death time (MDT) similar to the parent strain AF2240-I. Moreover, rAF possessed an introduced mutation which was maintained for several passages. The entire rescue using the one-step assembly procedure was completed within a few weeks, which is extremely fast compared to previously used methods.
\end{abstract}

\begin{tabular}{ll}
\multicolumn{2}{l}{ Abbreviations } \\
rAF & Recombinant AF2240-I \\
RNP & Ribonucleoprotein complex \\
h p.t. & Hours post-transfection \\
h p.i. & Hours post-infection \\
ICPI & Intracerebral pathogenicity index \\
NDV & Newcastle disease virus \\
HDV Rz & HDV virus ribozyme \\
(-)ssRAA & Negative-sense single-stranded RNA
\end{tabular}

Khatijah Yusoff

kyusoff@upm.my

$\triangle$ Aidin Molouki

a.molouki@rvsri.ac.ir

1 Institute of Bioscience, Universiti Putra Malaysia, Serdang, Selangor, Malaysia

2 Department of Microbiology, Faculty of Biotechnology and Biomolecular Sciences, Universiti Putra Malaysia, 43400 Serdang, Selangor DE, Malaysia

3 Department of Virology, Wageningen Bioveterinary Research, Lelystad, The Netherlands

4 Department of Avian Disease Research and Diagnostic, Razi Vaccine and Serum Research Institute, Agricultural Research Education and Extension Organization (AREEO), Karaj, Iran

\section{Introduction}

Newcastle Disease (ND) is a potential threat to commercial poultry production. This disease spreads rapidly in chickens and other birds and is caused by avian orthoavulavirus-1, commonly known as Newcastle disease virus (NDV) [1]. The genome of NDV, abiding by the rule-of-six [2], contains a non-segmented single-stranded negative-sense RNA with a length of $15,186,15,192$ or 15,198 nucleotides (nt) [3]. The structural genome contains six genes, which encode (in $3^{\prime}-5^{\prime}$ order) the nucleoprotein (NP), phosphoprotein $(\mathrm{P})$, matrix protein $(\mathrm{M})$, fusion protein $(\mathrm{F})$, hemagglutininneuraminidase $(\mathrm{HN})$, and large (L) polymerase protein [4]. During replication, two non-structural proteins known as $\mathrm{V}$ and $\mathrm{W}$ are also produced through RNA editing of the $\mathrm{P}$ gene [5]. The initiation of an infectious cycle of a negative-sense RNA virus such as NDV requires the presence of a complete ribonucleoprotein (RNP) complex consisting of the genomic RNA and the NP, $\mathrm{P}$ and L proteins since the naked RNA genome is not infectious $[6,7]$.

The various strains of NDV can be classified into different pathotypes based on the degrees of disease severity in birds [8]; asymptomatic strains cause a subclinical enteric infection without any clinical manifestations. Lentogenic strains are of low-virulence and may produce mild respiratory signs 
or enteric disease in young chickens. Mesogenic strains exhibit intermediate virulence causing respiratory disease in young birds and decreased egg production in laying flocks. Viscerotropic velogenic and neurotropic velogenic strains are highly virulent and cause different severe clinical signs such as diarrhoea and frequent haemorrhagic intestinal lesions, and neurotropic disease symptoms respectively [9]. However, NDV is also genetically classified based on the sequence of its F gene [10]. The Malaysian NDV strain AF2240-I is a viscerotropic velogenic genotype VIII strain [11] that was first isolated in Malaysia in the 1960s. The oncolytic potential of this strain has been studied both in vitro and in vivo. Overall, it has been demonstrated that AF2240-I possesses the ability to induce apoptosis in many cancer cell lines such as MCF7, HCT116, HT29 and HeLa [12-14].

Reverse genetics systems for several NDV strains have been developed in the past $[6,7,15-20]$. These systems rely on cloning of the full-length NDV cDNA in a suitable transcription vector followed by co-transfection with helper plasmids expressing the viral NP, $\mathrm{P}$ and L proteins in suitable cells [21]. Based on the preferred system, the cells are either pre-infected with helper recombinant poxviruses carrying the T7 RNA polymerase gene, or stably express this polymerase (e.g. BSRT7/5 cells). In addition, Pol II-based rescue systems have also been reported in recent years [22, 23].

Traditionally, there are two major methods used to sequentially assemble the NDV full-length cDNA into transcription vectors. The first and most frequently used strategy is based on using natural or artificially introduced RE sites $[6,7,15,17]$. Several cDNA fragments spanning the entire genome of NDV are created and then they are joined at overlaps using shared RE sites. This strategy is based on a technique first published by Schnell et al. 1994 for rescue of rabies virus [24]. The other strategy for assembly of the full-length cDNA is based on a ligation-independent cloning (LIC) technique [18], in which $\mathrm{Hu}$ and colleagues used an In-Fusion ${ }^{\circledR}$ PCR system to amplify fragments using primers that contained a 15-nt overlapping region of homology on $5^{\prime}$ ends. These fragments were sequentially assembled in a modified pBluescript, which was linearized before each phase of In-Fusion ${ }^{\circledR}$ reaction. This strategy has been gaining more popularity in recent years for its ease of use compared to the RE-based strategy [19, 20, 25-27].

Both of the above procedures are time-consuming and challenging. In the current study, we report the generation of rNDV from a completely synthetic full-length cDNA, a new rapid strategy for cloning the whole $\sim 15 \mathrm{~kb}$ genome, which requires only one cloning step. This work is patented [28] and was also recently used to generate an IL12-expressing rNDV which was then used in an anti-cancer study [29]. Here we describe the methodology by which the original rAF was generated.

\section{Materials and Methods}

\section{Construction of pOLTV5-phiX}

Transcription vector pOLTV5 [9] was modified to insert a phiX region (taken from the high-copy number vector pTVT7R $(0,0)$-phiX, kindly provided by Dr. Andrew Ball, Department of Microbiology, University of Alabama, Birmingham, AL, USA) by utilising the SapI and BamHI RE sites to generate low-copy number vector pOLTV5-phiX (3020 bp). The phiX region contains BbsI RE sites at both ends (reverse at $5^{\prime}$ and forward at $3^{\prime}$ ends) to facilitate the insertion of full-length AF2240-I cDNA in pOLTV5-phiX between the T7 promoter and the Hepatitis Delta virus ribozyme (HDV Rz) by a single cloning step.

\section{Construction of Full-Length cDNA}

To assemble the full-length AF2240-I cDNA into the pOLTV5-phiX vector, the full-length genome cDNA was synthesised and cloned by GenScript, NJ, USA. The synthetic cDNA contained BsmBI RE sites (forward at the 5' end and reverse at $3^{\prime}$ end) and three overhanging nucleotides at both ends to facilitate cloning (Fig. 1). To follow the rule-of-six, the additional $\mathrm{G}$ residues that are traditionally added after the $\mathrm{T} 7$ promoter transcription initiation site were not synthesised. A single natural BsmBI RE site, at position 6741 within the genome cDNA, was mutated by replacing $\mathrm{G}$ with A (CGTCTC to CATCTC) to serve as a genetic marker. The change did not alter the amino acid sequence of the HN protein. The synthesised cDNA was then digested with BsmBI RE. Meanwhile, pOLTV5-phiX was digested with $B b s I$ RE resulting in overhangs complementary to full-length cDNA BsmBI digestion. When digested, the vector would therefore produce cohesive $5^{\prime}$ ends bearing the sequence $5^{\prime}$-TATA- ${ }^{\prime}$ and $5^{\prime}$-GGGT$3^{\prime}$ overhangs. Consequently, the synthesised rAF cDNA when digested with $B s m \mathrm{BI}$ produced cohesive $5^{\prime}$ ends, 5'-TATA-3' and 5'-ACCC-3' overhangs. Subsequently, the rAF full-length cDNA genome was ligated into pOLTV5phiX vector targeting the $p h i \mathrm{X}$ region to generate the plasmid pOLTV5-AF (17,565 bp). The full-length cDNA was placed right after the T7 promoter (without any additional guanine residues behind the promoter) and before the HDV Rz motif on the plasmid (Fig. 1). To increase the plasmid copy number, CopyCutterTM Induction Solution (Epicentre, USA) was added to induce and artificially increase the plasmid copy number at its log phase followed by an overnight incubation at $37{ }^{\circ} \mathrm{C}$ and a constant shaking at $300 \mathrm{rpm}$ for $18-20 \mathrm{~h}$. The transformation of large plasmid was enhanced using DH10 $\beta^{\mathrm{TM}}$ competent $E$. coli cells 


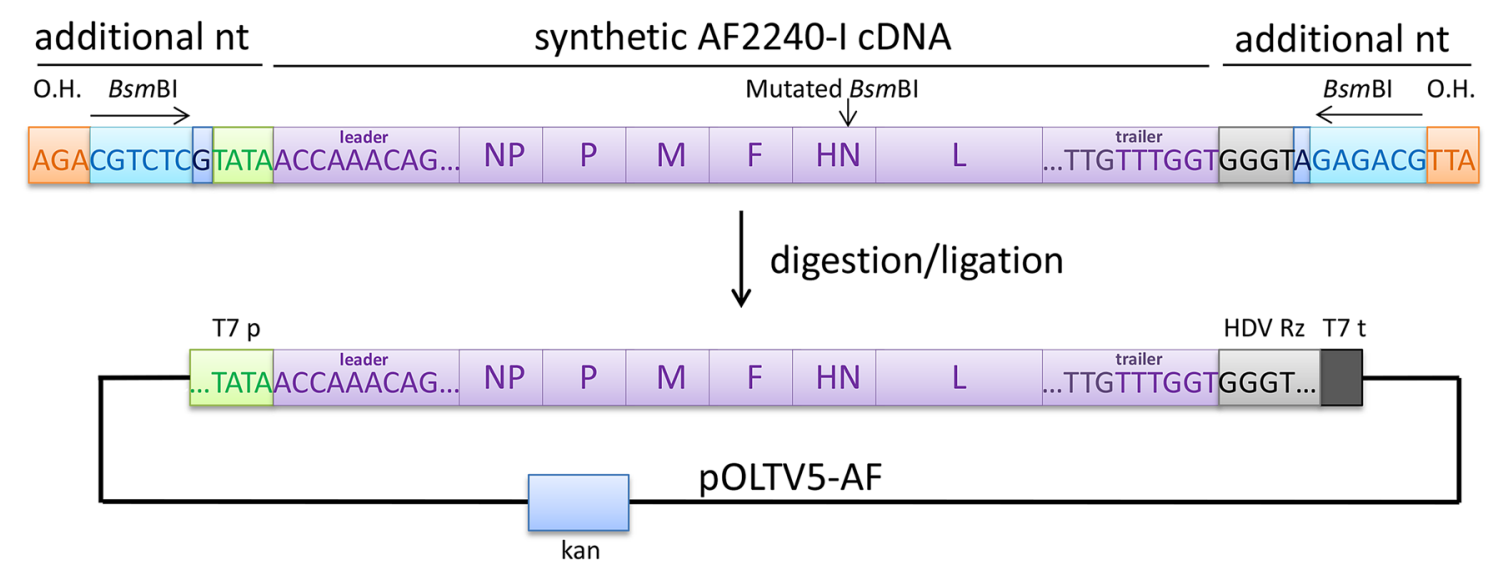

Fig. 1 Plasmid pOLTV5-AF was produced by utilising the BbsI RE site in the $p h i \mathrm{X}$ region of pOLTV5-phiX. AF2240-I genome was synthesised to contain BsmBI RE at the 5' and 3' ends. Final size of the synthetic cDNA was 15,220 bp. A naturally present BsmBI within

(Thermo Scientific, USA) which are intended for higher transformation efficiency. Bacteria cultures were grown in $2.5 \mathrm{~L}$ of $\mathrm{LB}$ medium and a maximum concentration of $1 \mathrm{mg}$ plasmid was obtained.

\section{Construction of Helper Plasmids}

To construct the three helper plasmids, the open reading frames (ORFs) of the NP, P, and L genes were amplified from the AF2240-I cDNA using specific primers, and then cloned into pJET cloning vector. The primers used to amplify the NP, P and L genes were NP-Fwrd (5'-CTTG CTCGAGACCATGTCTTCCGTATTCGATGAA-3'), NPRvrse (5'-CTTGGCGGCCGCTCAATACCCCCAGTC GGT-3'), P-Fwrd (5'-AGACCTCGAGACCATGGCCACC TTTACAGAT-3'), P-Rvrse (5'-AGACGCGGCCGCTTA GCCATTTAGTGCAAGGCG-3'), L-Fwrd (5'-CAGAGCT AGCTGGTCAGCATACATAATATTCGGCTGACGT $-3^{\prime}$ ) and L-Rvrse (5'-CTTGGTCGACGATAACTATGCG CACTCCTGTTTTAAGATAATTATTTGAATCCGAATA C-3') (XhoI, NotI, SalI and NheI are in bold and a Kozak's sequence in italic). The genes were then RE digested and cloned into pCIneo (Promega, USA) between XhoI and NotI to generate $\mathrm{pCIneo-NP/AF}$ and $\mathrm{pCIneo-P/AF}$ respectively and $S a l I$ and NheI to generate pCIneo-L/AF.

\section{Rescue of Virus}

Baby hamster kidney cell line stably expressing the phage T7 RNA polymerase (BSRT7/5) (kindly provided by Prof. Karl-Klaus Conzelmann, Munich, Germany) were grown in Glasgow's modified essential media (GMEM) (Sigma Aldrich, USA), supplemented with $10 \%$ newborn calf serum (NCS), $1 \%$ tryptose-phosphate, $1 \%$ pen/strep and the HN gene was mutated to not interfere with cloning. pOLTV5$p h i \mathrm{X}$ was digested with $B b s \mathrm{I}$ to create matching sticky ends with the BsmBI-digested synthetic genome. The AF2240-I genome was ligated to be located between the $\mathrm{T} 7$ promoter and HDV Rz region

MEM amino acids. Selection for the T7 RNA polymerase gene was done by using $1 \mathrm{mg} / \mathrm{mL}$ of G418 (Sigma, USA) in every second passage. To rescue recombinant AF2240-I, BSRT7/5 cells were grown to $80 \%$ confluency in six-well plates and were co-transfected using pOLTV5-AF and different ratios of the helper plasmids $[6,7,15,16,22]$ using Lipofectamine ${ }^{\mathrm{TM}} 2000$ plus (Invitrogen, Thermo Fisher Scientific) according to the supplier's instructions. As a negative control, pOLTV5-AF was co-transfected with a set of helper plasmids in which pCIneo-L was replaced with pEGFP.N2 (Clontech, USA). At $16 \mathrm{~h}$ post-transfection (p.t.), the media was removed and stored in $4{ }^{\circ} \mathrm{C}$. The cells were then cultured in fresh GMEM medium. After 4 days $(96 \mathrm{~h}$ p.t.), the culture supernatant and cells from the transfected monolayers were harvested by scraping. The clarified and unclarified supernatants were inoculated separately into the allantoic cavities of 9- to 11-day-old specific pathogen-free (SPF) embryonated chicken eggs. After $48 \mathrm{~h}$ all embryos were checked for viability. Allantoic fluid of all eggs was harvested. The purified recombinant virus was checked for hemagglutinating activity (HA).

\section{Determining Recombinant Virus Stability and Pathogenicity}

To further check the stability of the genetic marker, the rAF virus was successively passaged 5 times in 9- to 11-day-old embryonated SPF eggs. The virulence of the recovered virus and the wild-type virus was determined by the mean death time (MDT) and the intracerebral pathogenicity index (ICPI) according to OIE guidelines [8]. Briefly, the MDT assay was performed by making ten-fold dilutions of allantoic fluid to obtain dilution series between $10^{-6}$ and $10^{-9}$. For each dilution, $100 \mu \mathrm{L}$ was inoculated into the allantoic cavity of 
each of five 9-day-old SPF eggs. Another five eggs were inoculated $8 \mathrm{~h}$ later as recommended. The incubated eggs were examined twice daily for 7 days and the times of any embryo death were recorded. The MDT was the mean time in hours for the minimum lethal dose to kill all the inoculated embryos. Furthermore, the ICPI was performed by tenfold diluting a fresh NDV-positive allantoic fluid in sterile isotonic saline and injecting $500 \mu \mathrm{L}$ of it intracerebrally into each of ten 1-day-old SPF chicks. The chicks were examined every day for 8 days. At each observation the birds were scored 0 if normal, 1 if sick and 2 if dead. The ICPI was the mean score per bird per observation over the 8-day period. Generally, highly virulent strains will demonstrate scores between 1.5 and 2 .

\section{Ethical Clearance}

Animal handling procedures were performed in line with the national animal welfare regulations. All animal experiments were approved by the Institutional Animal Care and Use Committee (IACUC), Faculty of Veterinary Medicine, Universiti Putra Malaysia (UPM) (reference number UPM/ IACUC/AUP-R051/2014) and conducted in a BSL-2 facility in UPM, Selangor, Malaysia.

\section{Results}

\section{Full-Length cDNA Synthesis}

The fully synthetic rAF cDNA was successfully inserted into the T7-transcription plasmid pOLTV5-phiX (a derivative of pOLTV5). In the resulting plasmid pOLTV5-AF, the full-length rAF cDNA is flanked by the T7 RNA promoter and the HDV Rz sequence. In the presence of T7 RNA polymerase, this allows the generation of full-length vRNA (fulllength viral RNA transcribed from plasmid DNA) with the precise authentic $3^{\prime}$ and $5^{\prime}$ ends of the genomic (-)RNA of NDV.

\section{Virus Recovery}

Transfection of BSRT7/5 cells was performed using pOLTV5-AF and the, NP-, P- and L-helper plasmids. The cell culture medium was collected at $16 \mathrm{~h}$ and $96 \mathrm{~h}$ p.t. The $16 \mathrm{~h}$ p.t. samples were clarified to remove cell debris, whereas the 96 h p.t. samples were either clarified or not. Clarified and unclarified samples were subsequently inoculated into embryonated SPF eggs. Embryo death from all supernatant sources was observed after $48 \mathrm{~h}$ of incubation, indicating the presence of infectious virus. Embryo death was not observed in eggs inoculated with control supernatant from transfections in which the L-helper plasmid was omitted. Allantoic fluid was harvested and all showed positive HA.

To identify the recovered virus as recombinant AF2240I the presence of the mutated BsmBI RE site genetic marker was confirmed by RT-PCR and DNA sequencing (Fig. 2). These results convincingly indicate successful rescue of $\mathrm{rAF}$ from the pOLTV5-AF infectious cDNA clone.

\section{Pathogenicity and Genetic Stability}

rAF virus showed a MDT of $48 \mathrm{~h}$ in chicken embryos compared to $46.8 \mathrm{~h}$ for the wild-type strain AF2240-I. This indicated that the pathogenicity of rAF was similar to that of wild-type AF2240-I.

Since the ICPI allows for a closer characterisation of virus pathogenicity, rAF and wild-type AF2240-I were used to determine the ICPI in 1-day-old chicks. The ICPI for rAF was 1.83 , whereas the ICPI for the wild-type strain was 1.81 .

To verify that the recombinant strain is phenotypically and genetically stable, rAF was passaged up to five times in embryonated eggs. All passaged strains showed ICPI values which were close to that of the parent strain (Table 1). In virus from each of the five passages, the presence of the mutated BsmBI RE site within the HN gene was confirmed by sequencing analysis (Fig. 2). This indicates that the synonymous mutation was stably maintained for five passages.

Furthermore, the effect of rAF on cancer cell lines such as HeLa was investigated (Fig. 3). Membrane blebbing and detachment of cells from surface were evident at $24 \mathrm{~h}$ p.i.

\section{BsmBI}

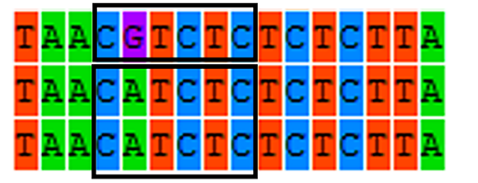

AF2240-I

Synthesised cDNA

rAF

Mutated BsmBI
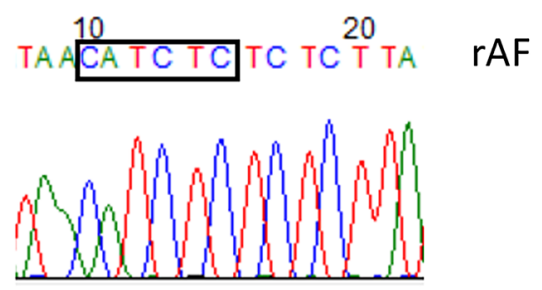

Fig. 2 Presence of genetic marker was confirmed. DNA sequencing showed that the naturally occurring BsmBI RE site was mutated in $\mathrm{rAF}$ and the mutation maintained for five passages 
Table 1 MDT and ICPI of rAF remained constant for five passages

\begin{tabular}{lll}
\hline Passage no. & MDT & ICPI \\
\hline rAF-p1 & 48 & 1.83 \\
rAF-p2 & 49 & 1.84 \\
rAF-p3 & 47.8 & 1.85 \\
rAF-p4 & 47 & 1.83 \\
rAF-p5 & 48 & 1.84 \\
Wild-type & 46.8 & 1.81 \\
\hline
\end{tabular}

The first rescued strain was tagged as rAF-p1, and thereafter passages labelled as rAF-p2, rAF-p3, rAF-p4, rAF-p5. All five passages killed all embryos within $49 \mathrm{~h}$ indicating that the strains are virulent. A more efficient determination is by ICPI which recorded at value between 1.81 and 1.85 which are within the range of a positive velogenic strain NDV

\section{Discussion}

In this study, the recombinant Malaysian strain AF2240-I was successfully rescued from a completely synthetic fulllength cDNA clone. This is a new and rapid strategy for the generation of rNDV and, as far as we know, rAF is the first NDV to be rescued by this method. The design of the transfection vector pOLTV5-phiX greatly assisted in the ligation of the synthetic cDNA and may be a useful tool for future rescue work using other strains of NDV.

In pOLTV5-AF, the leader sequence was placed immediately after the $\mathrm{T} 7$ promoter without any additional $\mathrm{G}$ residue(s). Traditionally, at least two or three $\mathrm{G}$ residues are added after the $\mathrm{T} 7$ promoter to increase the efficiency of transcription. These residues are removed during replication and the recovered viruses do not carry them [24, 30,

31]. To fully follow the rule-of-six, the AF2240-I cDNA was synthesised without the additional $\mathrm{G}$ residues. The idea behind this was to include the original genome size $(15,192 \mathrm{~b})$, without any additional nucleotides, between the T7 promoter and the HDV Rz. The results showed that the first residues of leader sequence (the first residue is an $\mathrm{A}$, which is also a purine) can efficiently rescue $\mathrm{rAF}$ from pOLTV5-AF. This suggests that, for a rule-of-six virus, the incorporation of $\mathrm{G}$ residues in such non-helper virus systems (in this case the BSRT7/5 cells) may not be needed. Furthermore, since the efficiency of virus recovery was high, no further comparison between rescue with or without additional $\mathrm{G}$ residues was performed.

The RE-based and LIC strategies are time-consuming and may take several weeks to complete, especially if a new strain has to be sequenced and cloned. These strategies require many cloning steps that are usually complicated and need a high level of molecular expertise. In contrast, pOLTV5-AF was created by only one ligation procedure. In this study, generation of rAF was completed within just a few weeks. Therefore, this approach certainly has major advantages over previously used strategies.

pOLTV5 originates from plasmid pOK12 which carries the replicon from P15A [32], resulting in a relatively lowcopy number. A low-copy number plasmid was chosen as a transcription vector as it is particularly useful for large plasmids which may cause the metabolic burden to become too large for the host cell causing plasmid-bearing cells to grow slowly [33]. pOLTV5 vector is able to stably replicate large inserts such as the genome of NDV [7].

One of the most important requirements for successful virus rescue is the availability of the correct co-transfection components consisting of helper plasmids that express the functional NP, $\mathrm{P}$ and $\mathrm{L}$ proteins. The ratios of helper plasmids used in previous publications $[6,7,15,16,22]$ varied accordingly to different strains hence in the current work we tested which ratio was best suited for the rescue of strain
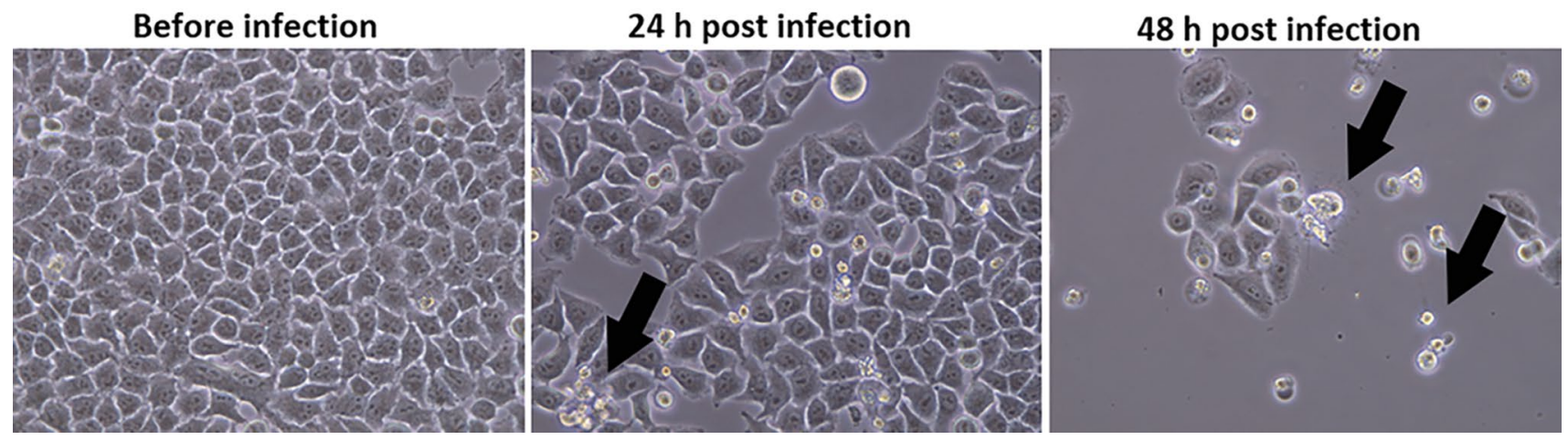

Fig. 3 Effect of rAF on HeLa cancer cell line (MOI=10). The cells underwent membrane blebbing and detached from the surface. Black arrows indicate the apoptotic cells 
AF2240-I. Conventionally, the ratios of the transfected NP, $\mathrm{P}$ and $\mathrm{L}$ plasmids were calculated considering the lengths of $6942 \mathrm{nt}, 6660 \mathrm{nt}$ and 12,087 nt of the expression plasmids, respectively. Particularly for RNA replication, a constant nucleocapsid synthesis is required [34] and a high level of NP expression may favour the initial nucleocapsid formation. Nevertheless, our results indicate that all ratios regardless of their correspondence to plasmid lengths were able to produce infectious viral particles (data not shown).

Typically, optimum transient gene expression from plasmid DNA can be noticed approximately $24-96 \mathrm{~h}$ post-transfection [35]. For NDV recovery, cell supernatant containing budded viral particles are harvested, usually optimally at $96 \mathrm{~h}$ p.t. In the current study, inoculation of $16 \mathrm{~h}$ p.t. supernatant resulted in infectious virus particle propagation in embryonated eggs. This suggests that, the viral titre in the supernatant $16 \mathrm{~h}$ p.t. was sufficient to initiate the production of infectious viral particles by embryonated eggs. Because of the frequent use, all possible means to reduce the time needed for the reverse genetics process will definitely help in speeding up the generation of recombinant virus. In addition, the cell supernatant is usually clarified (to remove cell debris) prior to inoculation into embryonated egg, although the use of cell lysate for inoculation has also been reported [18]. In this study we also showed that it was not necessary to remove cell debris from the cell supernatant and that the supernatant of cell media can be directly inoculated into embryonated chicken eggs without affecting virus recovery.

The mean times to kill all embryos are $48 \mathrm{~h}$ and $46.8 \mathrm{~h}$ respectively for rAF and AF2240-I. A highly virulent strain would supposedly take below $60 \mathrm{~h}$ to kill all embryonated eggs. Hence we can conclude that, based on the MDT, the rAF is a highly virulent strain similarly to its wild-type. Although the MDT of rAF showed a slight increase compared to wild-type AF2240-I by $2.8 \mathrm{~h}$, both strains are still categorised as highly virulent strains. For the remaining passages of the strains, i.e. passage 2, passage 3, passage 4 and passage 5, the MDT were also determined and recorded at $49 \mathrm{~h}, 47.8 \mathrm{~h}, 47 \mathrm{~h}$, and $48 \mathrm{~h}$, respectively (Table 1). This shows that after five passages, the virulence of the recombinant virus remains high. The virulence of the passaged viruses was also tested in chickens by ICPI test. The index values indicated that recombinant virus from all passages was velogenic, equivalent to wild-type AF2240-I. The ICPI results coupled with MDT is an adequate indication of virulence stability.

Sequence analysis of the complete genome showed that the mutated BsmBI RE site was maintained after five passages. This allowed us to ascertain that minor modifications to the genome that do not affect the rule-of-six or proteinencoding regions will be stable after at least five passages. In fact, over the last two decades recombinant NDVs have shown to be very stable viruses after several passages and may have very low mutation rates [36]. This also includes the stability of foreign genes inserted into the genome. Therefore, in this study mutation analysis after more passages was not conducted. However, a recent rescue of an IL12-expressing rAF proves the construct to be very reliable as its stability maintained for ten passages [29].

The successful rescue of the rabies virus [24], as well as the rescue of the two VSVs shortly thereafter [37, 38], were important milestones in virology as the technique provided the opportunity to genetically modify the genome of many other negative-sense RNA viruses such as Sendai virus [39, 40], measles virus [41], human para influenza [42, 43], Nipah virus [44] and NDV [7]. These developments have provided the opportunity to elucidate the function of NDV genes and proteins in determining virulence and tropism [45]. Reverse genetics has also allowed the development of NDV as a vaccine vector. Due to the ability of NDV to act as a vector to transiently but strongly express foreign genes, its application as a tool for gene therapy and vaccine vector has been studied. This applies for both animal and human use [46-48]. Another important application of the reverse genetics technology is the development of negative-strand viruses, particularly NDV, for cancer research [49-52].

New advances in whole genome sequencing, such as nextgeneration sequencing (NGS), as well as advances in chemical synthesis, such as the rapid synthesis of long cDNA fragments, may be very valuable if a recombinant virus or vaccine is urgently needed. By the rapid method introduced in this study the synthetic viral cDNA may be easily customised according to specific needs. Current research interests on recombinant NDV are mainly focussing on adding various additional properties [53]. Therefore it is of high interest to assure that the current rescue procedure is also applicable for all future work to produce rNDV for poultry vaccine development or human cancer research.

Acknowledgements KM was supported by a Graduate Research Fellowship, UPM and MyPhD Scholarship by Ministry Higher Education, Government of Malaysia.

Author Contributions KM and AM performed the experiments. KM wrote the manuscript. AM revised the manuscript. BP, AM and KM designed and planned the experiments. ARO and KY supervised the project and provided resources.

Funding The study was supported by funds from HICOE Grant, Minister of Higher Education, Government of Malaysia.

\section{Compliance with Ethical Standards}

Conflict of interest The authors do not have any competing interests to declare.

Animal and Human Rights Statement All institutional and national guidelines for the care and use of laboratory animals were followed. 


\section{References}

1. Walker PJ, Siddell SG, Lefkowitz EJ, Mushegian AR, Dempsey DM, Dutilh BE, Harrach B, Harrison RL, Hendrickson RC, Junglen S, Knowles NJ, Kropinski AM, Krupovic M, Kuhn JH, Nibert M, Rubino L, Sabanadzovic S, Simmonds P, Varsani A, Zerbini FM, Davison AJ (2019) Changes to virus taxonomy and the International Code of Virus Classification and Nomenclature ratified by the International Committee on Taxonomy of Viruses (2019). Arch Virol 164(9):2417-2429. https://doi.org/10.1007/ s00705-019-04306-w

2. Kolakofsky D, Pelet T, Garcin D, Sp H, Curran J, Roux L (1998) Paramyxovirus RNA synthesis and the requirement for hexamer genome length: the rule of six revisited. J Virol 72(2):891-899

3. Czeglédi A, Ujvári D, Somogyi E, Wehmann E, Werner O, Lomniczi B (2006) Third genome size category of avian paramyxovirus serotype 1 (Newcastle disease virus) and evolutionary implications. Virus Res 120(1-2):36-48. https://doi. org/10.1016/j.virusres.2005.11.009

4. Ganar K, Das M, Sinha S, Kumar S (2014) Newcastle disease virus: current status and our understanding. Virus Res 184:7181. https://doi.org/10.1016/j.virusres.2014.02.016

5. Steward M, Vipond IB, Millar NS, Emmerson PT (1993) RNA editing in Newcastle disease virus. J Gen Virol 74(Pt 12):2539-2547

6. Romer-Oberdorfer A, Mundt E, Mebatsion T, Buchholz UJ, Mettenleiter TC (1999) Generation of recombinant lentogenic Newcastle disease virus from cDNA. J Gen Virol 80(Pt 11):2987-2995

7. Peeters BP, de Leeuw OS, Koch G, Gielkens AL (1999) Rescue of Newcastle disease virus from cloned cDNA: evidence that cleavability of the fusion protein is a major determinant for virulence. J Virol 73(6):5001-5009

8. Manual of Diagnostic Tests and Vaccines for Terrestrial Animals (mammals, birds and bees) (2012) Terrestrial Manual. OIE, World organization for animal health, 7th edn, vol 1

9. Alexander DJ (1997) Newcastle disease and other avian Paramyxoviridae infections. In: Calnek BW, with Barnes HJ, Beard CW, McDougald LR, Saif YM (eds) Diseases of poultry, 10th edn. Mosby-Wolfe, London, pp 541-570

10. Dimitrov KM, Abolnik C, Afonso CL, Albina E, Bahl J, Berg M, Briand FX, Brown IH, Choi KS, Chvala I, Diel DG, Durr PA, Ferreira HL, Fusaro A, Gil P, Goujgoulova GV, Grund C, Hicks JT, Joannis TM, Torchetti MK, Kolosov S, Lambrecht B, Lewis NS, Liu H, Liu H, McCullough S, Miller PJ, Monne I, Muller CP, Munir M, Reischak D, Sabra M, Samal SK, Servan de Almeida R, Shittu I, Snoeck CJ, Suarez DL, Van Borm S, Wang Z, Wong FYK (2019) Updated unified phylogenetic classification system and revised nomenclature for Newcastle disease virus. Infect Genet Evol 74:103917. https://doi.org/10.1016/j. meegid.2019.103917

11. Murulitharan K, Yusoff K, Omar AR, Molouki A (2013) Characterization of Malaysian velogenic NDV strain AF2240I genomic sequence: a comparative study. Virus Genes 46(3):431-440. https://doi.org/10.1007/s11262-012-0874-y

12. Molouki A, Yusoff K (2012) NDV-induced apoptosis in absence of Bax; evidence of involvement of apoptotic proteins upstream of mitochondria. Virol J 9:179. https://doi. org/10.1186/1743-422X-9-179

13. Molouki A, Hsu YT, Jahanshiri F, Abdullah S, Rosli R, Yusoff K (2011) The matrix (M) protein of Newcastle disease virus binds to human bax through its BH3 domain. Virol J 8:385. https://doi.org/10.1186/1743-422X-8-385

14. Molouki A, Hsu YT, Jahanshiri F, Rosli R, Yusoff K (2010) Newcastle disease virus infection promotes Bax redistribution to mitochondria and cell death in HeLa cells. Intervirology 53(2):87-94. https://doi.org/10.1159/000264198

15. Nakaya T, Cros J, Park MS, Nakaya Y, Zheng H, Sagrera A, Villar E, Garcia-Sastre A, Palese P (2001) Recombinant Newcastle disease virus as a vaccine vector. J Virol 75(23):11868-11873

16. Huang Z, Krishnamurthy S, Panda A, Samal SK (2001) High-level expression of a foreign gene from the most $3^{\prime}$-proximal locus of a recombinant Newcastle disease virus. J Gen Virol 82(Pt 7):1729_ 1736. https://doi.org/10.1099/0022-1317-82-7-1729

17. Krishnamurthy S, Huang Z, Samal SK (2000) Recovery of a virulent strain of Newcastle disease virus from cloned cDNA: expression of a foreign gene results in growth retardation and attenuation. Virology 278(1):168-182. https://doi.org/10.1006/ viro. 2000.0618

18. Hu H, Roth JP, Estevez CN, Zsak L, Liu B, Yu Q (2011) Generation and evaluation of a recombinant Newcastle disease virus expressing the glycoprotein $(\mathrm{G})$ of avian metapneumovirus subgroup $\mathrm{C}$ as a bivalent vaccine in turkeys. Vaccine 29(47):86248633. https://doi.org/10.1016/j.vaccine.2011.09.007

19. Yu Q, Roth JP, Hu H, Estevez CN, Zhao W, Zsak L (2013) Protection by recombinant Newcastle disease viruses (NDV) expressing the glycoprotein $(\mathrm{G})$ of avian metapneumovirus (aMPV) subtype A or B against challenge with virulent NDV and aMPV. World J Vaccines 3(4):130-139. https://doi.org/10.4236/wjv.2013.34018

20. Li J, Hu H, Yu Q, Diel DG, Li DS, Miller PJ (2012) Generation and characterization of a recombinant Newcastle disease virus expressing the red fluorescent protein for use in co-infection studies. Virol J 9:227

21. Molouki A, Peeters B (2017) Rescue of recombinant Newcastle disease virus: a short history of how it all started. Arch Virol 162(7):1845-1854. https://doi.org/10.1007/s00705-017-3308-2

22. Zhang X, Liu H, Liu P, Peeters BP, Zhao C, Kong X (2013) Recovery of avirulent, thermostable Newcastle disease virus strain NDV4-C from cloned cDNA and stable expression of an inserted foreign gene. Arch Virol 158(10):2115-2120

23. Liu H, Albina E, Gil P, Minet C, de Almeida RS (2017) Twoplasmid system to increase the rescue efficiency of paramyxoviruses by reverse genetics: the example of rescuing Newcastle disease virus. Virology 509:42-51. https://doi.org/10.1016/j.virol .2017 .06 .003

24. Schnell MJ, Mebatsion T, Conzelmann KK (1994) Infectious rabies viruses from cloned cDNA. EMBO 13(18):4195-4203

25. Zhao W, Hu H, Zsak L, Yu Q, Yang Z (2013) Application of the ligation-independent cloning (LIC) method for rapid construction of a minigenome rescue system for Newcastle disease virus VG/GA strain. Plasmid 70(3):314-320. https://doi.org/10.1016/j. plasmid.2013.07.005

26. Zhao W, Spatz S, Zhang Z, Wen G, Garcia M, Zsak L, Yu Q (2014) Newcastle disease virus (NDV) recombinants expressing infectious laryngotracheitis virus (ILTV) glycoproteins gB and gD protect chickens against ILTV and NDV challenges. J Virol 88(15):8397-8406. https://doi.org/10.1128/jvi.01321-14

27. Zhang Z, Zhao W, Li D, Yang J, Zsak L, Yu Q (2015) Development of a Newcastle disease virus vector expressing a foreign gene through an internal ribosomal entry site provides direct proof for a sequential transcription mechanism. J Gen Virol 96(8):2028-2035

28. Yusoff K, Omar AR, Molouki A, Murulitharan K, Lin CS, Chin CL (2017) Reverse genetics system to provide a recombinant viscerotropic virulent genotype VIII Newcastle disease virus (NDV) strain AF2240-I (rAF). Malaysian Patent PI 2017701829

29. Mohamed Amin Z, Che Ani MA, Tan SW, Yeap SK, Alitheen NB, Syed Najmuddin SUF, Kalyanasundram J, Chan SC, Veerakumarasivam A, Chia SL, Yusoff K (2019) Evaluation of a recombinant Newcastle disease virus expressing human IL12 against human breast cancer. Sci Rep 9(1):13999. https://doi.org/10.1038/s4159 8-019-50222-z 
30. Pattnaik AK, Ball LA, LeGrone AW, Wertz GW (1992) Infectious defective interfering particles of VSV from transcripts of a cDNA clone. Cell 69(6):1011-1020

31. Peeters BP, Gruijthuijsen YK, de Leeuw OS, Gielkens AL (2000) Genome replication of Newcastle disease virus: involvement of the rule-of-six. Arch Virol 145(9):1829-1845

32. Vieira J, Messing J (1991) New pUC-derived cloning vectors with different selectable markers and DNA replication origins. Gene 100:189-194

33. Nordstrom K, Austin SJ (1989) Mechanisms that contribute to the stable segregation of plasmids. Annu Rev Genet 23:37-69. https ://doi.org/10.1146/annurev.ge.23.120189.000345

34. Patton JT, Davis NL, Wertz GW (1984) N protein alone satisfies the requirement for protein synthesis during RNA replication of vesicular stomatitis virus. J Virol 49(2):303-309

35. Kim TK, Eberwine JH (2010) Mammalian cell transfection: the present and the future. Anal Bioanal Chem 397(8):3173-3178. https://doi.org/10.1007/s00216-010-3821-6

36. Kim SH, Samal SK (2016) Newcastle disease virus as a vaccine vector for development of human and veterinary vaccines. Viruses 8(7):183. https://doi.org/10.3390/v8070183

37. Whelan SP, Ball LA, Barr JN, Wertz GT (1995) Efficient recovery of infectious vesicular stomatitis virus entirely from cDNA clones. Proc Natl Acad Sci USA 92(18):8388-8392

38. Lawson ND, Stillman EA, Whitt MA, Rose JK (1995) Recombinant vesicular stomatitis viruses from DNA. Proc Natl Acad Sci USA 92(10):4477-4481

39. Garcin D, Pelet T, Calain P, Roux L, Curran J, Kolakofsky D (1995) A highly recombinogenic system for the recovery of infectious Sendai paramyxovirus from cDNA: generation of a novel copy-back nondefective interfering virus. EMBO 14(24):6087-6094

40. Kato A, Sakai Y, Shioda T, Kondo T, Nakanishi M, Nagai Y (1996) Initiation of Sendai virus multiplication from transfected cDNA or RNA with negative or positive sense. Genes Cells 1(6):569-579

41. Radecke F, Spielhofer P, Schneider H, Kaelin K, Huber M, Dötsch C, Christiansen G, Billeter MA (1995) Rescue of measles viruses from cloned DNA. EMBO 14(23):5773-5784

42. Durbin AP, Hall SL, Siew JW, Whitehead SS, Collins PL, Murphy BR (1997) Recovery of infectious human parainfluenza virus type 3 from cDNA. Virology 235(2):323-332. https://doi.org/10.1006/ viro.1997.8697

43. Hoffman MA, Banerjee AK (1997) An infectious clone of human parainfluenza virus type 3. J Virol 71(6):4272-4277
44. Yoneda M, Guillaume V, Ikeda F, Sakuma Y, Sato H, Wild TF, Kai C (2006) Establishment of a Nipah virus rescue system. Proc Natl Acad Sci USA 103(44):16508-16513. https://doi. org/10.1073/pnas.0606972103

45. Dortmans J, Koch G, Rottier P, Peeters B (2011) Virulence of newcastle disease virus: what is known so far? Vet Res 42(1):122

46. Liu Q, Mena I, Ma J, Bawa B, Krammer F, Lyoo YS, Lang Y, Morozov I, Mahardika GN, Ma W, Garcia-Sastre A, Richt JA (2015) Newcastle disease virus-vectored $\mathrm{H} 7$ and $\mathrm{H} 5$ live vaccines protect chickens from challenge with $\mathrm{H} 7 \mathrm{~N} 9$ or $\mathrm{H} 5 \mathrm{~N} 1$ avian influenza viruses. J Virol. https://doi.org/10.1128/JVI.00031-15

47. Zamarin D, Vigil A, Kelly K, García-Sastre A, Fong Y (2009) Genetically-engineered Newcastle disease virus for malignant melanoma therapy. Gene Ther 16(6):796-804. https://doi. org/10.1038/gt.2009.14

48. Schirrmacher V, Fournier P (2009) Newcastle disease virus: a promising vector for viral therapy, immune therapy, and gene therapy of cancer. Methods Mol Biol 542:565-605. https://doi. org/10.1007/978-1-59745-561-9_30

49. Reichard KW, Lorence RM, Cascino CJ, Peeples ME, Walter RJ, Fernando MB, Reyes HM, Greager JA (1992) Newcastle disease virus selectively kills human tumor cells. J Surg Res 52(5):448-453

50. Shobana R, Samal SK, Elankumaran S (2013) Prostate-specific antigen-retargeted recombinant Newcastle disease virus for prostate cancer virotherapy. J Virol 87(7):3792-3800. https://doi. org/10.1128/JVI.02394-12

51. Fiola C, Peeters B, Fournier P, Arnold A, Bucur M, Schirrmacher V (2006) Tumor selective replication of Newcastle disease virus: association with defects of tumor cells in antiviral defence. Int J Cancer 119(2):328-338. https://doi.org/10.1002/ijc.21821

52. Zamarin D, Palese P (2012) Oncolytic Newcastle disease virus for cancer therapy: old challenges and new directions. Future Microbiol 7(3):347-367

53. Fournier P, Schirrmacher V (2013) Oncolytic Newcastle disease virus as cutting edge between tumor and host. Biology 2(3):936975. https://doi.org/10.3390/biology2030936

Publisher's Note Springer Nature remains neutral with regard to jurisdictional claims in published maps and institutional affiliations. 